\title{
Unplatformed Design: A Model for Appropriating Social Media Technologies for Coordinated Participation
}

\author{
Daniel Lambton-Howard', Patrick Olivier², Vasilis Vlachokyriakos', Hanna Celina', \\ Ahmed Kharrufa ${ }^{1}$ \\ ${ }^{1}$ Open Lab, Newcastle University, Newcastle-upon-Tyne, UK \\ \{d.howard2, vasilis.vlachokyriakos1, h.celina1, ahmed.kharrufa\}@newcastle.ac.uk \\ ${ }^{2}$ Action Lab, Monash University, Melbourne, Australia, patrick.olivier@monash.edu
}

\begin{abstract}
Using existing social media technologies as a resource for design offers significant potential for sustainable and scalable ways of coordinating participation. We look at three exemplar projects in three distinct domains that have successfully coordinated participation through the configuration and augmentation of existing social media technologies: participatory future forecasting, participatory health research, and connectivist learning. In this paper we conceptualise social media technologies as material for design, that is, as a raw material with which coordinated participation is realized. From this we develop a model that proposes four material qualities of social media technologies, morphology, role, representation of activity and permeability, and point to how they can be productively employed in the design of coordination of participation.
\end{abstract}

Author Keywords

Social media; materiality; design of participation

CSS Concepts

- Human-centered computing Interaction design theory, concepts and paradigms • Human-centered computing $\sim \mathrm{HCI}$ theory, concepts and models

\section{INTRODUCTION}

Designing ways for citizens, stakeholders and communities to participate in projects is a key concern of organizations, institutions and researchers. Coordinating participation, that is the creation of processes, activities and tools that seek to engage people in working towards a particular goal, may be oriented towards data collection, decision making, insight generation, ideation, activism and more. Although the goals of participation are varied, they all face similar design challenges such as how to motivate and engage participants; how to structure collaboration and communication, and how to provide effective channels of participation.

Permission to make digital or hard copies of part or all of this work for personal or classroom use is granted without fee provided that copies are not made or distributed for profit or commercial advantage and that copies bear this notice and the full citation on the first page. Copyrights for third-party components of this work must be honored. For all other uses, contact the Owner/Author.

CHI '20, April 25-30, 2020, Honolulu, HI, USA

(C) 2020 Copyright is held by the owner/author(s).

ACM ISBN 978-1-4503-6708-0/20/04

https://doi.org/10.1145/3313831.3376179
At the same time, social media technologies are increasingly being incorporated into the mechanisms of civic life. These technologies are frequently referred to as 'platforms' as they act as base technologies upon which a multitude of social activities occur. Civic activities on social media platforms range from transactional services such as the use of WhatsApp for delivering court summons in India [33], to patients using social media to track and report health conditions [19], to entirely self-organized groups within social activism [12]. These increasingly varied uses of globally accessible digital platforms bring to the fore an alternative to conventional ways of designing bespoke technologies and platforms for participation, through designing the social structures and processes (e.g. governance) and technical infrastructures (e.g. aggregator websites) that build on top of existing digital technologies. Although the utility of this genre of system design has begun to be demonstrated, a proper understanding of this approach has yet to be articulated.

To this end, we look at three examples of the appropriation of existing social media technologies for coordinating participation, each in distinct domains: Asynchronous Remote Communities [29] (participatory health research), Online UWC [6] (connectivist MOOCs) and WhatFutures [25] (participatory strategic foresight). These examples represent a broad range of domains, deployment scales and technologies, but are common in their attempts to democratically engage participants on the social media technologies that they are already using. By social media technologies, we are not only referring to social media websites and applications (e.g. Twitter, Instagram), but also messaging applications (e.g. WhatsApp, Messenger, Viber) and those which incorporate wider activities such as shopping and digital games (e.g. Facebook, WeChat).

We propose a conceptualization of social media technologies as design materials with material qualities. In this paper we focus on the utilization of these material qualities for enabling coordinated participation. This allows us to chart a design space, within which we surface how the design decisions of each case study have configured (directly manipulated) and augmented (added to or otherwise enhanced) the material qualities of social media technologies in support of coordinating participation. In contrast to prevailing tendencies to build new and bespoke platforms to 
meet the challenges of coordinating participation, we propose a model of unplatformed design. We refer to it as unplatformed in that it does not involve the creation of new platforms to sustain a process of participation, but rather utilizes the materiality of existing social media technologies.

The contributions of this paper are: 1) a conceptualization of social media technologies as design material, along with a corresponding articulation of their material qualities in respect to coordinated participation; 2) a design model for coordinated participation through the configuration and augmentation of social media's material qualities, as demonstrated through three case studies.

\section{RELATED WORK}

\section{Designing for Appropriation}

The identification of factors that affect the successful appropriation of technology has been an area of interest within $\mathrm{HCI}$, and specifically $\mathrm{CSCW}$, for a number of years. Dourish [15] focussed on how technical elements of software directly affects its suitability to adaptation by users and identified a set of broad principles to inform software design. Dourish also argues that an understanding of the technical aspects, as well as social conditions, is crucial for an understanding of system adoption. Wulf and Pipek [36] have done extensive work in understanding the relationships between collaborative and creative activities and technological infrastructures that are necessary for appropriation. Alan Dix [14] identified a set of heuristics to support designers who wish to create software in ways that makes appropriation by end users easier and more likely. One of these heuristics - to learn from the ways that technology has already been appropriated - is particularly relevant. Although Dix defines this as informing the design a new tool by looking closely at what aspects of other technologies have been appropriated by users, we might extend this idea to ask what we can learn from the practice of appropriation itself. That is, we might look at how coordinated participation has been enacted through the appropriation of existing technologies.

\section{Social Media Technologies as Participation}

HCI has long been concerned with the ways in which social media technologies have been appropriated for uses beyond their standard use cases, both by citizens and by organisations. One area of research that has emerged from this concern is the field of crisis informatics. Since 2001, considerable work has been undertaken in understanding the utility of social media in communicating critical information during and after a crisis. Of particular relevance, Starbird and Palen [35] conducted a study of the self-organisation of volunteers during the 2010 Haiti earthquake, noting how systematic use of hashtags and micro-syntax led Twitter (as well as a collection of other social media technologies) to be more effectively used to coordinate digital volunteerism. Similarly Cobb et al. [9] studied social media use during crisis events, and identified ad hoc collaborative practices employed by digital volunteers that helped with handling the 'deluge' of digital information. Consequently, they proposed a series of design recommendations for tools that could be used to support these practices whilst still maintaining the crucial flexibility of social media use. Research in crisis informatics points to the value of systematic and considered use of social media technologies for effective coordination of participation in volunteerism.

Digital civics is an area of HCI that generally operates in a non-commercial and values driven research space where the appropriation of existing technology is often motivated for both pragmatic and democratic reasons. The use of social media technologies for public engagement is one such area. Hou and Lampe [21] conducted a survey of 26 non-profit organisations and identified both the potential value of social media technologies in public engagement work, but also limiting factors (such as constraints in time, funding, expertise and organisational politics). They proposed a set of design considerations to overcome these limitations, focussing on the use of external management and analytics tools and organisational change. Similarly, Crivellaro et al. [11] used social media technologies to support a communitywide consultation on the future of parks and green spaces within a city. They highlight the value brought by a series of structured Twitter engagements in contributing to the building of collaborative spaces within the consultation, but also illustrate tensions resulting from their use.

Research into citizen led appropriation social media technologies has frequently focused on ad hoc appropriation practices. For example, Voida et al. [39] describe how volunteer coordinators at non-profit organizations use a mix of homebrew databases and associated information management tools, identifying the shortcomings of an approach (e.g. insufficient features, clumsy interfaces, integration failures) that is born out of necessity. These finding are also evidenced by Wiggins [43] who reports how resource-constrained citizen science projects similarly struggle with freely available software. These findings highlight how the purposeful and systematic appropriation of existing social media technologies may offer a compelling set of design opportunities, as opposed to ad hoc and make shift practices.

\section{COORDINATING PARTICIPATION WITH SOCIAL MEDIA}

Our related work is extended by our analysis of three indepth case studies. Our approach takes three examples of coordinated participation that share the common quality of being enacted through existing social media technologies, due to operating within resource constrained contexts. We scrutinize the design rationales behind each study in order to unpick design decisions and we examine reported reflections upon the benefits, limitations and general implications of designing on social media technologies.

In order to ensure consistency in our approach, based upon insights from appropriation literature cited above, we pay particular attention to the use of tools in respect to how each case study recruits, combines and coordinates different 
technologies in order to achieve a goal of coordinated participation [14,15,37]. We also pay particular attention to the social structures, activity and information flow in relation to how the conditions of participation are created and sustained $[15,18,38]$. This provides a consistent analytical lens with which to establish commonalities across the case studies. Following the account of these three studies, we then abstract and theorize as to these commonalities.

We now summarise the following: Asynchronous Remote Communities [29], Online UWC [6] and WhatFutures [25]. These case studies span a broad range of domains, social media technologies and scales of participation. Despite this all three are united by their resource constrained contexts of deployment and in their attempts to democratically engage participants on the social media technologies that they are already using, as opposed to (potentially unsuccessfully) migrating them onto new or unfamiliar technologies.

Case Study 1: Health Research with Distributed Populations, Asynchronous Remote Communities (ARC) MacLeod et al. [29] developed the Asynchronous Remote Communities (ARC) research method in order to overcome limitations inherent to co-located and synchronous research methods used within traditional human-centered health research. ARC was designed to generate workshop and/or focus group qualitative data from communities such as pregnant women and new mothers [34], teenagers experiencing stress [1] and people living with rare diseases [29], by communicating with them on a social media platform they are already using.

The ARC method brings together a group of participants in a digital environment (e.g. a closed and hidden Facebook group) to complete a set of assigned individual or collaborative activities. These activities are posted periodically within the group and include forms of traditional human-centred research methods such as lightweight icebreaker activities, diary-keeping, photo elicitation, persona development, as well as psychometric tests and surveys. Primarily participants post their text or image responses directly into the group, however other tools can also be employed to collect different types of data, such as bespoke survey tools for survey data and audio services (e.g. Google Voice) for audio recordings.

Through reflection on a series of deployments of the ARC method, Maestre et al. identify a series of lessons for the design of similar studies that use online platforms. For example, the importance of 'posting activities and reminders on the same day every week' [30] and, in a reference to the way some platforms (e.g. Facebook) curate what content is seen by users, Macleod et al. [29] observe that researchers should be prepared to adopt multiple approaches to ensure activities are seen by participants'.

Perhaps most interestingly, Maestre et al. point to the ways in which studies that take place on existing platforms can be alternatively designed, and the reasons why researchers may want to do this [30]. Variables that they suggest may be altered include choice of platform (for reasons of data ownership, privacy, or features that simplify data analysis or allow for different kinds of interaction), activities and their frequency, study length, sample size and participant groupings and group size (to suit different research goals and populations). The importance of weighing up the "pros and cons' when choosing platforms for ARC is further elucidated by Kresnye et al. [5]

Case Study 2: Connectivist Online Learning, Online UWC Within the domain of informal education, Celina et al. [6] designed a series of connectivist open online courses in collaboration with United World Colleges (UWC), that used existing social media platforms as central infrastructure for the learning activity. Their stated intention was that this infrastructural approach would enable participants to democratically select their preferred communication channels in support of their autonomy as learners. This would reduce the risk of a central structure, or locus of teaching, pre-determining learning pathways and constraining innovation, as well as lowering any technological barriers to participation.

Celina et al. ran three courses under the umbrella of Online UWC, one based primarily through 'loosely-coupled' social media [6]. These courses used Google Course Builder as a central website for course scheduling and materials, and relied on a loose ecosystem of social media (Facebook, Google + ) messaging and communication platforms (WhatsApp, Skype, Google Hangouts, email) for discussions and group activities. The learning was assisted by assigning participants to particular roles: mentors who helped students understand the material; student chairs who led and directed group discussions; and course coordinators who helped with logistics and timings. As well as these formal roles, the courses also placed a particularly strong emphasis on selforganization by students.

Infrastructuring the courses in this way was found to increase overall engagement, particularly in respect to promoting community, as many of the groups created during these courses persisted after the course had concluded. However, Celina et al. noted the challenges of providing clear and unambiguous communication to participants about logistics and learning expectations when no central platform was used and particularly when working at scale across multiple platforms.

Celina et al. also reflected upon the different usage patterns between a bespoke learning platform, LearningCircle.io [7], and usage patterns on loosely-coupled social media technologies. They concluded that "using a variety of platforms that are natively used by learners can more prominently and naturally lead to the creation of lasting social bonds that survive the course... A 'platform' for a connectivist inspired course should integrate and organise [social] media, not aim to displace it. " [7] 


\section{Case Study 3: Strategic Foresight, WhatFutures}

In 2017, the International Federation of Red Cross and Red Crescent Societies (IFRC) sought to engage their global young volunteers in a large-scale, participatory, strategic foresight activity. The IFRC had historically struggled to engage this populations with traditional survey methods, and so, in collaboration with Lambton-Howard et al. [25], designed and delivered WhatFutures, a 10-day online engagement event, WhatFutures employed the messaging application WhatsApp to gather rich qualitative data in support of the IFRC's strategic project to develop a 10-year strategy. WhatsApp was chosen as the primary method of engagement due to its widespread use in the developing world, particularly by young volunteers in resource constrained contexts.

WhatFutures was designed to be an engaging small team game event, where teams of participants would respond to creative challenges. These included producing news stories about a challenge facing their society in 2030, and recording audio and video messages to the general secretary of the IFRC about an innovative response to a crisis in 2030. To support understanding of the complexity of global issues, each participant chose a unique role to play in their team (environmental scientist, cultural expert, technologist, political advisor). These roles, and corresponding identity and team duties, were further constructed through an interlinking system of WhatsApp group chats. In these chats participants would have access to a large group of others who shared the same role, but were from different teams. As data from WhatsApp groups cannot be automatically exported, Administrators (named 'Future Guides') were also in each team, and assisted in the exporting of multimedia data to a shared Google Drive and posting the game's challenges in the form of image files. Updates were then posted on an external website 'leader board', where each team could view and comment on all the responses to the game's challenges.

WhatFutures was piloted in June 2017 with 5 countries, and 487 participants generating 95 multimedia artefacts and over 16,000 messages in support of IFRC's strategic foresight project. Reportedly, "the game was highly successful at attracting a diverse audience directly and maintaining a substantive dialogue, an outcome that most other previous attempts have failed at." This is attributed "primarily to the utilization of a popular existing communication service that was familiar to the intended player base' - significantly lowering barriers to participation.

In reflecting on the process of designing with WhatsApp, Lambton-Howard et al. identified four qualities of the social media technology: morphology, role, externalisation and process. Respectively, these refer to connections between users, a user's functions within a system, representation of data outside of a system, and the rules that structure a process. It is these relatively undeveloped concepts that we use as a starting point for our model of unplatformed design.

\section{THINKING MATERIALLY}

Through examination of these case studies, we identify commonalities in respect to how they recruit, combine and coordinate different technologies, as well as how they construct and support specific social behaviours and practices. These commonalities exist, despite the variety in modes of participation, due to the need to democratically engage participants in resource constrained contexts. To help us formalise these commonalities into a useful model, a core element of our abstraction is to conceptualise social media technologies as design material. This allows us to establish a consistent approach in our abstraction that eschews typical understandings of social media technologies and their ingrained usage patterns, and enables us to see more clearly how they have been appropriated.

The conceptualization of digital technologies as material has history within HCI, most notably in Löwgren \& Stolterman's "Thoughtful Interaction Design" [27] and Eli Blevis' "Regarding Software as a Material of Design”[2]. Whereas these works sought to situate software as a material product of design, and therefore warranting of an appropriately rigorous design process and designerly evaluation (arguably now an established perspective), our conceptualization instead positions social media technologies as material for design, that is, as the raw material with which something else is realized - namely coordinated participation.

Our understanding of materiality follows Dourish [16] who described the materiality of information as "those properties of representations and formats that constrain, enable, limit and shape the ways in which those representations can be created, transmitted, sorted, manipulated and put to useproperties like robustness, consistency, compressibility, malleability..." Or to put it bluntly, the way information is materially configured ultimately affects what we can do with it. Just as it is useful for a carpenter to understand how the material qualities of a piece of wood (grain, hardness, pliability etc) affect the qualities of the final table, so it is useful for designers of coordinated participation to appreciate how the material qualities of social media technology (e.g. how information is presented, how connections are formed between users) will impact on the activities and processes they seek to coordinate with those technologies.

In each of these case studies, decisions have been made to manipulate the base material of an adopted social media technology (e.g. using the group function on a messaging application to create teams, disseminating information by using the upload function etc). We refer to these set of design decisions as configuration, as they refer to the direct manipulation of elements intrinsic to media technologies. This is in line with current theory which views the active configuration of technical infrastructure as being a crucial component to the work of appropriating technologies [36].

These case studies also bring to light a separate design space that exists beyond the boundaries of the technical 


\begin{tabular}{|c|c|c|c|}
\hline Morphology & ARC & Online UWC & WhatFutures \\
\hline Configuration & $\begin{array}{l}\text { Number of groups: typically } 1-3 \\
\text { Group size: } \sim 15 \\
\text { Relationship between participants: } \\
\text { group membership }\end{array}$ & $\begin{array}{l}\text { Number of groups: dynamic } \\
\text { Group size: } 2-10 \text { average } \\
\text { Relationship between participants: } \\
\text { dynamic, group membership }\end{array}$ & $\begin{array}{l}\text { Number of groups: } \sim 100 \\
\text { Group size: } 4-8 \text { average } \\
\text { Relationship between participants: } \\
\text { group membership }\end{array}$ \\
\hline $\begin{array}{l}\text { Hard } \\
\text { Augmentation }\end{array}$ & Email recruitment for participants & $\begin{array}{l}\text { Central website (Google Course } \\
\text { Builder / Bespoke Website) } \\
\text { Google Hangouts and assignments } \\
\text { Private Facebook groups }\end{array}$ & $\begin{array}{l}\text { Central website } \\
\text { Shared Google documents between } \\
\text { administrators }\end{array}$ \\
\hline $\begin{array}{l}\text { Soft } \\
\text { Augmentation }\end{array}$ & $\begin{array}{l}\text { Building of strong connections } \\
\text { between researcher and potential } \\
\text { participants pre-recruitment }\end{array}$ & Students sharing contact information & $\begin{array}{l}\text { Administrative rules creating a } \\
\text { 'hierarchy' of groups }\end{array}$ \\
\hline
\end{tabular}

Table 1. Configuration and augmentation of morphology in the 3 case studies.

infrastructure of the adopted social media technologies. For example, both Online UWC and WhatFutures involved the creation of an external website to facilitate resource sharing and public presentation respectively, whilst all three case studies employed a small set of tools to facilitate the capturing of data. These effectively act as extensions to the base material of the adopted social media technology within the context of the coordinated participation. To revisit the analogy of making a wooden table, we can see these as the addition of other materials to improve the overall design, such as the inclusion of metal supports or application of protective lacquers. In contrast to configuration, we refer to these set of design decisions as hard augmentation, in that they enhance and expand upon the base material with additional material.

Furthermore, beyond consideration of technical infrastructure of the case studies, we can also see a set of design elements that are entirely social in nature (e.g. divisions of labour and expertise, establishing of norms, and the setting of procedures and tasks). To understand these we borrow the concept of 'practice' from Wenger's communities of practice [41]. Wenger states that 'practice is, first and foremost, a process by which we can experience the world and engagement with it as meaningful'. This is useful to us, as it helps surface the design elements in these case studies that establish the 'practice' of the coordinated participation. For example, the communication work that transforms a particular Facebook group into a health research study with an established set of behaviours and responsibilities; or that turns a WhatsApp group into a competitive team; or, to push our analogy further, that tells us that a chunk of wood with four legs is either a dinner table or a work desk. We refer to these set of design decisions as soft augmentation.

In summary, there is a distinction between the configuration of material (the arrangement and combination of elements intrinsic to a social media technology, e.g. the use of a private Facebook group in ARC), the hard augmentation of material (the introduction and combination of additional technologies, e.g. the external aggregator website in
WhatFutures), and soft augmentation of material (the establishment of agreed practices and social behaviours, e.g. student mentor roles in Online UWC).

In order to understand in detail, the ways in which configuration and augmentation of material has occurred within the case studies we need a more nuanced understanding of materiality. To this end we conceptualize social media technologies in terms of material qualities. This gives us a level of explanatory granularity that is lacking from more general descriptions. Lambton-Howard et al. [25] proposed an initial categorization of material qualities of WhatsApp (morphology, role, externalisation and process), which we adapt and build upon in relation to coordinated participation. However, as our abstraction is focussed on material qualities we have not included 'process', as its temporal dimension makes it conceptually distinct to a material quality. As such we discuss it separately. Furthermore, we do not consider 'externalisation' as a useful quality to our model as it is a relatively undeveloped concept that refers to how information is outputted from WhatsApp. Instead we propose two new qualities. The first, representation of activity, refers to how information is represented generally (following Dourish) both internally and externally. The second, permeability, is based on our reflections of information flow within the case studies and concerns the ways in which data and information are transferred within a coordinated participation.

In summary we have identified four primary material qualities of coordinated participation through social media technologies: morphology, role, representation of activity and permeability. Using these material qualities as the basis of our understanding, we now present evidence gathered from the meta-analysis of three empirical case studies, and discuss the ways in these qualities have been configured and augmented in support of coordinated participation.

\section{MORPHOLOGY}

A core characteristic of social media technologies is the realization of sociality through connections and relationships between users. Borrowing this term from biological sciences, the material quality of morphology refers to the overall form 


\begin{tabular}{l|lll} 
Role & ARC & Online UWC & WhatFutures \\
\hline Configuration & $\begin{array}{l}\text { Administrative rights: group } \\
\text { administration restricted to } \\
\text { researchers } \\
\text { Authorial permissions: open to all }\end{array}$ & $\begin{array}{l}\text { Administrative rights: dynamic, } \\
\text { negotiated between participants } \\
\text { Authorial permissions: open to all }\end{array}$ & $\begin{array}{l}\text { Administrative rights: group } \\
\text { administration restricted to game } \\
\text { facilitators and organizers. } \\
\text { Authorial permissions: open to all }\end{array}$ \\
$\begin{array}{l}\text { Hard } \\
\text { Augmentation }\end{array}$ & & $\begin{array}{l}\text { Administrative rights on central } \\
\text { course website restricted to } \\
\text { organizers of Online UWC }\end{array}$ & $\begin{array}{l}\text { Editing rights of shared Google } \\
\text { Drive documents restricted to } \\
\text { research team }\end{array}$ \\
$\begin{array}{l}\text { Soft } \\
\text { Augmentation }\end{array}$ & $\begin{array}{l}\text { Research participant privileges and } \\
\text { expectations } \\
\text { Researcher role }\end{array}$ & $\begin{array}{l}\text { Mentor role } \\
\text { Student chair role }\end{array}$ & $\begin{array}{l}\text { Player specialisms (environmental, } \\
\text { cultural, political, technological) } \\
\text { 'Future guide' administrator role } \\
\text { Game master role }\end{array}$
\end{tabular}

Table 2. Configuration and augmentation of role in the 3 case studies.

and structure of these connections when viewed as a whole. These include, but are not limited to: group membership; group size; number of groups; friend relationships; following relationships and number of relationships.

As the nature of these connections differ, so do their implications on the interactions that take place on, and with, that system. Consider for example, the different available actions, and nature of interactions, between being in a group chat (e.g. WhatsApp), to being a 'follower' of someone (e.g. Instagram). In turn, size, membership criteria, and connectedness of groups characterize the qualities and dynamics of interactions between participants. This is of relevance to coordinated participation as the size and membership of groups has implications on factors such as mutual understanding, group cohesion, and capacity for decision making [24,28]. Additionally, connections between groups and individuals, realized through overlapping membership, may be a channel through which information and knowledge diffusion can occur (and can be influenced).

If we look at the morphologies of our case studies, we can shed light on the design features of the three systems and also elaborate on how the quality of morphology can impact on the coordination of participation. Table 1 shows how the case studies have configured the morphology of their adopted social media technologies. Compare ARC with WhatFutures, where the former typically configures between one and three groups $[5,29,34]$ as the locus of participation, (due to its relatively small participation size and sensitive subject matter), the latter configured multiple small independent WhatsApp groups (to facilitate competitive, team-based challenges).

Beyond this configuration of connections intrinsic to social media technologies, we can also see connections that occur externally. In Online UWC connections were made in the form of multiple private Facebook groups where learners discussed assignments. The administrators and organizers then hard augmented connections between these groups with a central scheduling website. These augmentations were not manifest in the Facebook groups themselves, but still constitute the overall morphological form of Online UWC.
WhatFutures imposed a 'hierarchy' of information and responsibility on top of WhatsApp groups. Some groups were specifically designated for administrators, with an organizer's and stakeholder's group above this. This hierarchy was not a configured aspect of the system, but instead was a soft morphological augmentation sustained by the organizers and administrators within those groups, and affected information flow and activity throughout the coordinated participation.

\section{ROLE}

The material quality of role concerns the communication, understanding and designation of a user's identity and understanding of the actions, duties and expectations related to that identity. For social media technologies, this is most often expressed through the implementation of a model of access and control. Examples of this include, but are not limited to administrative roles; authorial permissions (who 'owns' media); commenting rights; moderation roles and direct messaging rights.

Role is relevant to coordinated participation as it can be a powerful mechanism for scoping anticipated contributions of both participants and groups, and make expectations concerning division of labour explicit $[10,23]$. Role can also be understood through divisions of expertise (e.g. who is suited for what tasks) and divisions of perspective (e.g. different disciplinary traditions) to name a two examples. The quality of role is also affected by different distributions of power, disparities in information and societal expectations. In the case studies these differences, more often than not, were intended, and naturally affect the functions and actions that people perform [17].

Again, by looking at role in our case studies we shed light on the design features of the studies and on how the quality of role has been employed in coordinating participation. Table 2 shows how the case studies have configured role. Compare WhatFutures and ARC, where administrative privileges were restricted to researchers and coordinators (in order to ensure continued control over respective projects), with Online UWC, where group creation and administration was negotiated between participants (in support of the ideals of a connectivist MOOC). 


\begin{tabular}{|c|c|c|c|}
\hline $\begin{array}{l}\text { Representation } \\
\text { of Activity }\end{array}$ & ARC & Online UWC & WhatFutures \\
\hline Configuration & $\begin{array}{l}\text { Choice of media type: activities } \\
\text { primarily posted as text } \\
\text { Visibility of media: private } \\
\text { Curation of activity: pinned } \\
\text { activities }\end{array}$ & $\begin{array}{l}\text { Choice of media type: video } \\
\text { discussions, text posts and images } \\
\text { Visibility of media: private within } \\
\text { group activities and within } \\
\text { Facebook groups }\end{array}$ & $\begin{array}{l}\text { Choice of media type: primarily } \\
\text { text, but image used for challenges } \\
\text { and image and video solicitation. } \\
\text { Visibility of media: private within } \\
\text { WhatsApp group chats }\end{array}$ \\
\hline $\begin{array}{l}\text { Hard } \\
\text { Augmentation }\end{array}$ & $\begin{array}{l}\text { Mobile application prototype (in } \\
{[30] \text { ) }}\end{array}$ & $\begin{array}{l}\text { Central focal point website, used for } \\
\text { scheduling and organization }\end{array}$ & $\begin{array}{l}\text { Central focal point website, used for } \\
\text { leader board and further engagement }\end{array}$ \\
\hline $\begin{array}{l}\text { Soft } \\
\text { Augmentation }\end{array}$ & $\begin{array}{l}\text { Activity post titles marked as } \\
\text { [ACTIVITY] to improve visibility }\end{array}$ & & $\begin{array}{l}\text { Curation and selection of participant } \\
\text { activity for public and other } \\
\text { participants }\end{array}$ \\
\hline
\end{tabular}

Table 3. Configuration and augmentation of representation of activity in the 3 case studies.

In the case studies, the hard augmentation of role occurred when access permissions need to be controlled for external technologies, such as Google Drive permissions in WhatFutures and central website administration in Online UWC.

However, the most effective manipulation of role in respect to coordinated participation can be found where it has been soft augmented. In WhatFutures, the system-level designation of WhatsApp group administrator (and the associated system privileges that affords) was soft augmented with the role of 'Future Guide'. The Future Guide role communicated an expectation of conduct, expertise, a duty of care, and a set of procedural responsibilities with respect to the transfer of information and media.

Furthermore, four additional roles were created in WhatFutures to express different types of expertise. These roles were assigned externally to WhatsApp, and had no distinction at a system level. Nevertheless, they acted to support the division of labour within group activities, to provide multiple perspectives on complex issues and to support the overall morphology of the unplatformed design (role was used to determine group membership). A similar approach was adopted by Online UWC where student chairs and mentors were assigned to lead discussions and learning. Within ARC, the identity of participants was explicitly soft augmented with the role of being a 'research participant', and so was accompanied with requests for consent, and the communication of the associated 'privileges' of being able to leave the study at any point and general rules around conduct/participation and data capture.

\section{REPRESENTATION OF ACTIVITY}

Representation of activity is the manner and methods by which the activity of participants is presented, curated and navigated, either within a social media technology or externally. By activity we are referring to the products of participants' interactions with each other and the system, such as posts made on Facebook, media uploaded to WhatsApp, tweets and direct messages. By representation, we are adopting Dourish's [16] assertion of representation of information as not being merely abstract, but as having critical consequences for what we can do with it (e.g. sort, transmit, navigate, comprehend and otherwise manipulate).
Examples of system level configurations of representation of activity are multitudinous, and include (but are not remotely limited to): choice of media type; message threading; media interactions (e.g. likes, follows, favourites, retweets etc); tagging/categorization of media; curation of activity (e.g. pinning posts, discovery algorithms); Visibility of media (private $\rightarrow$ public) and persistence of media.

For coordinated participation, decisions around how, when and whether activity is made visible may drive behavior, knowledge exchange and a sense of collective action or competition [25]. Consider the difference between a direct timeline of messages (WhatsApp) compared to threaded replies and comments (Facebook). The former is more facilitative of 'in-the-moment' messaging and focusses conversation towards one narrative as multiple conversations become hard to follow in a group. Threaded conversations are easier to follow but evoke a sense of fragmented activity that can be difficult to manage in complex tasks [22].

Features that allow the navigation and surfacing of historical activity (e.g. through search functions, tags, or otherwise) have an effect on the potential complexity of collaborative tasks. They may support or inhibit the ability of users to manage large amounts of information and multiple sources [22]. Similarly, curation of activity, referring to decisions around which activity to make visible (e.g. the order of posts on a Facebook timeline) is also an important factor and is particularly relevant when curation is performed by oblique algorithms that decide the primacy of pieces of activity and flag them as popular, relevant or neither [29].

Table 3 shows how the three case studies configured representation of activity and how these relate to the coordination of participation. In ARC, activity was posted within a Facebook group where participants could engage at their own pace without worrying that content might disappear completely or be hard to find later. This supported the overall flow of the study and enabled the social media group to act as a repository for the participants' activity. This is contrasted with Online UWC, where the primary activity was live discussion. Often held through group video conferencing, this led to a more dynamic and impermanent representation of activity. Although the accompanying use of Facebook groups (for more organizational conversations) 


\begin{tabular}{l|lll} 
Permeability & ARC & Online UWC & WhatFutures \\
\hline Configuration & $\begin{array}{l}\text { Researchers used standard } \\
\text { Facebook input methods. }\end{array}$ & $\begin{array}{l}\text { Video conferencing functionality } \\
\text { of Google Hangouts } \\
\text { Facebook groups }\end{array}$ & $\begin{array}{l}\text { 'Export chat' for outputting data } \\
\text { Administrators used standard } \\
\text { WhatsApp input methods. }\end{array}$ \\
Hard Augmentation & $\begin{array}{l}\text { Google forms / Survey Monkey } \\
\text { for gathering survey information }\end{array}$ & $\begin{array}{l}\text { Use of loosely-coupled tools and } \\
\text { central website for scheduling, } \\
\text { tracking attendance, assignment } \\
\text { completion and feedback }\end{array}$ & $\begin{array}{l}\text { Shared Google Drive for } \\
\text { outputting multimedia data } \\
\text { Central website used for gathering } \\
\text { participant recruitment data }\end{array}$ \\
\cline { 2 - 2 } & $\begin{array}{l}\text { Data 'collected', through manual } \\
\text { copying and pasting of Facebook } \\
\text { interactions. }\end{array}$ & $\begin{array}{l}\text { Use of mentors in prep/delivery } \\
\text { Creation of class materials to } \\
\text { support discussions }\end{array}$ & $\begin{array}{l}\text { Administrator scheduled posting } \\
\text { of pre-prepared information } \\
\text { (challenges and deadlines) }\end{array}$
\end{tabular}

Table 4. Configuration and augmentation of permeability in the three case studies

provided a more permanent and navigable account. An example of configuration of media type can be found in WhatFutures, which represented the game's three challenges as image files (as opposed to text) so they were more easily identifiable and more easily forwarded between team groups.

In the case of both Online UWC and WhatFutures, representation of activity was hard augmented by the creation of an external website, acting as a permanent (and public) focal point, and enabling further commenting and activity. This choice has clear implications on the visibility and scope of coordinated participation. Within WhatFutures this enabled a perception of scale, of taking part in a project with large numbers of participants, and reportedly increased engagement and commitment to participation [31].

Although the public display of participant activity runs counter to the goals of ARC, representation of activity was soft augmented within their Facebook group by manually writing '[ACTIVITY]' in the title of posts that contained important research activities. This was to improve the visibility of these posts so that they stood out from general posts. Note that visibility of posts was also configured by using the 'pin post' functionality to increase prominence.

\section{PERMEABILITY}

The quality of permeability refers to the ways by which a system can receive, output and exchange information with other systems. As coordinated participation usually involves the transmission and collection of information and data in support of its goals, the ease in which this information flow can be enacted (i.e. how permeable a technology is) has significant implications for how it can be used to coordinate participation. Examples of system level configurations of permeability include, but are not limited to: methods of posting information or uploading media; methods for downloading content and media; formats of outputted data; availability and usability of APIs and in-system analytics.

For coordinated participation, the ways in which a system allows information to be input is a relevant concern. Manually entering information may make sense in smaller studies but quickly becomes impractical at scale. The availability of an API that allows the automated or bulk distribution of information then affects the design of a coordinated participation. The method of input also affects the quality of that communication. Automated or bulk communication has a different character to human inputted communication, and this will in turn affect how it is perceived and engaged with by participants [20].

Coordinated participation projects generally have a requirement to collect and analyse data. Interfaces that allow the output of information are therefore also of concern. Again, the availability of an API that can facilitate automated collection of information and data, (e.g. through scraping) can support data collection practices at scale. Likewise, the formats in which information and data can be collected and represented (e.g. raw text or formatted .json) change what can be done with it and so may entail different approaches to analysis and the introduction of external tools and software.

Related to both these concerns are the ways in which a social media technology interfaces with other systems. The more easily that information can be transferred between systems the more likely it is that external tools can be effectively employed. Celina et al. explored this idea in [6], and proposed the concept of ecosystems of systems as existing on a spectrum between being 'tightly-coupled' media (where systems interface through APIs) or 'loosely-coupled' media (where transfer of information between systems is performed by human operation, such as copy paste and manually downloading and uploading files).

Table 4 shows how permeability has been configured in the case studies. In each case the standard input methods of their chosen social media technologies were used for posting information and activities. The lack of a WhatsApp API led to WhatFutures using a team of administrators (Future Guides) for communicating with participants. This can be contrasted with ARC where standard input methods of Facebook were suitable for the smaller scale. Both Online UWC and WhatFutures augmented permeability by using a small collection of support tools for organizational communications, scheduling information and resource and data sharing. In ARC, Facebook data was manually collected, by copying and pasting into external documents, an example of a soft augmentation process. 


\section{DISCUSSION}

\section{Coordinated Participation as a Process}

One aspect that is absent from our descriptions of the material qualities of social media technologies, is time. Process, that is, decisions around when things should occur in a coordinated participation, was initially identified by Lambton-Howard et al. [25] as a material quality. But rather than treating process as a distinct material quality, we instead talk in terms of the temporal characteristics of the configuration and/or augmentation of the material qualities. For example, morphology was dynamic within Online UWC, ebbing and flowing according to the needs of participants as they engage in activities related to assignments. In WhatFutures the large conference WhatsApp groups, through which players connected with players from different teams who shared the same role, were not 'opened' until after an initial icebreaker period. Here the morphology of the engagement was changed over time to introduce complexity at a manageable rate for participants.

In our case studies, other material qualities changed over time, for example, participant assignment to a role in Online UWC changed between assignments in order to expose participants to different student mentors. Challenge outcomes within WhatFutures were published on the game's leader boards (an external representation of activity) at discrete points in time. Permeability, in respect to the posting of information, was tightly bound to a schedule with ARC, in order to create a suitable pacing of activities and expectation of contribution for participants. These examples show that the scheduling, duration or otherwise temporal characteristics of the configuration and augmentation of material qualities are a crucial component to coordinating participation with social media technologies.

\section{The Implications of Thinking Materially}

Social media technologies that have been adopted on a global scale, have been designed and optimised for specific usage patterns. Business models, underpinning these designs, take account of patterns of adoption, revenue generation and retention of users, etc. These patterns are often manifestly explicit, such as specific prompts for engagement and sharing of content, but also implicit, baked into the design of interfaces and algorithms themselves. They are hard to break away from, but thinking materially through the model presented here, allows us to frame them in new ways, effectively opening up a large, and until recently, relatively unexplored design space. Our intention behind this model is not to provide recommendations for how to design participation but rather to draw attention to new resources for design. As such we make the claim that the model presented here has descriptive utility and pragmatic utility.

The descriptive utility of the model is apparent in how the material qualities of the model, and the operations that can be applied to them (configuration and augmentation), allow us to isolate facets of existing systems that are difficult to describe without this conceptual apparatus. Indeed, when reflecting upon the case studies, what may have at first appeared to be three interesting but not essentially related systems, can now be seen more clearly as a set of designs based upon the materiality of social media. Crucially, this allows us to not only understand why design decisions have been made, but it also gives us a language to talk about them, to understand who made the decisions, for what purpose and to potentially identify why some decisions may be more or less successful than others in coordinating participation.

The pragmatic utility of thinking materially is in its value as a 'sensitizing concept' [3], an interpretive device that draws attention to the qualities of technologies that can be employed in design. Practically speaking, this will allow designers to reflect more clearly on the qualities of social media technologies not only in their suitability to a particular project (e.g. $[5,13]$ ), but also to be able to identify new possibilities as to how these qualities can be configured more effectively, augmented with external tools and software, or enhanced and coordinated through social processes. A first step in designing participation could be to identify which existing social media technologies are being used, and how these might be configured to support the goals of that participation. Thinking in this way makes it easier to perceive how a messaging application may be repurposed as peer support infrastructure and/or employed as data capture for a health intervention, or alternatively reconfigured as dynamic, low-tech communication hierarchy for volunteers responding to a crisis, to name just two examples.

Further exploration of this design space may also have implications on the design of social media technologies themselves. As unanticipated usage patterns and shortfalls of technologies are identified, social media technologies are modified to meet them. We can see this with Facebook's creation of specific health groups [26] with increased privacy controls and WhatsApp Business App [42] for increased options for tailoring and automation. Similar to how research around designing for appropriation [14,15,37] leads to a practical understanding of the elements of software design that lead to greater user customization, material understandings of social media technology may lead to them being designed with these material qualities in mind. This may entail changes to application infrastructure to better facilitate combination with external tools, or the creation of new flexible ways for users to communicate and coordinate social processes within technologies.

\section{The Implications of Configuration and Augmentation}

Configuration and augmentation, the operations performed to manipulate the material qualities of social media, are key elements of our model. But when is it best to configure and when is it best to augment a material quality? From the case studies we have seen that these decisions are in general based upon what best meets the functional requirements of a process, e.g. input and/or output of data, scheduling of activities, designation of roles. This is best expressed as the maxim 'configure as much as you can, and augment the 
rest'. This represents the perspective of making the most effective use of the available features of a social media technology, in that augmentation is used when certain desirable features are not available or are otherwise limited on a technology (e.g. the lack of export functionality necessitating manual capturing of data in all three case studies). But it also occurs when certain processes are sustained through social factors (e.g. the use of mentors and administrators in Online UWC and WhatFutures).

In this way, we can see that augmentation can occur at the boundary points of technologies. The implication of this, to borrow from ubiquitous computing, is that augmentation can be considered as an opportunity for seamful design [8]. Referring to the inevitable moments of failing (or the 'cracks') in interactions between ubiquitous computing devices, the notion of seams is a useful one to us. It has led researchers to propose that instead of trying to 'paper over' them, seams should instead be perceived as opportunities to increase the awareness for system infrastructures, their heterogeneous components and otherwise neglected yet useful information within the system. '[4] with Mark Weiser calling for the design of systems with 'beautiful seams' [40].

Relating this to the model presented here, augmentation should not be seen only in terms of overcoming the technical limitations of social media technology, but should instead be seen as an opportunity to improve and gain more control over a process of coordinated participation. Examples of this can be seen in WhatFutures, where the hard augmentation of an external website (initially intended to overcome a technical limitation of WhatsApp groups being unable to view each other's activity) provided an opportunity to improve the engagement through the creation of a publicly viewable leader board, increasing engagement levels and motivation.

In particular, the soft augmentation of 'seams' is a good way of improving a coordinated participation. For example, in Online UWC issues arising from unpredictable student attendance were more easily solved by the flexible and socially negotiated distribution of mentor and student chair roles, than if they were hard augmented or configured, i.e. being enforced at a system level. Furthermore, in WhatFutures the technical limitation of being unable to automatically export data from WhatsApp groups necessitated the inclusion of a dedicated human in each WhatsApp team to manually perform this duty. This presented an opportunity whereby this apparent 'seam' could instead be enhanced into an administrator role and improve the overall process by providing additional support for participants by answering questions and becoming an ambassador. It would be remiss however to not acknowledge some of the general disadvantages of designing with existing social media technologies, particularly in respect to issues around ownership of data, privacy, security and the potential for key features to change or be removed. The significance of these issues will vary between contexts, but should be considered in the design of coordinated participation.

\section{Unplatformed Design: from Prototype to Product}

Unplatformed design allows researchers an approach to coordinating participation that is robust, high fidelity and scalable. In this way, it can be seen as a step from designing research prototypes, to creating 'finished' artefacts. This is consistent with Odom et al.'s [32] call to move from research prototypes towards research products. Odom et al. argue that as the focus of HCI expands to investigate complex matters of human-technology relationships, designers must necessarily move from prototypes (which by definition are placeholders for some future thing) towards research products (as finished objects in their own right). This shift focuses the area of study from the potential of some designed thing to the study of what it actually is and how people actually interact with it, arguably a more accurate and authentic area of study of human-technological relationships.

Taking this further, when we reflect on the case studies we can see that each of them demonstrates an example of research responding to a real-world need. From ARC's gathering of real information to inform medical awareness of living with rare diseases (amongst others); to Online UWC's genuinely sustainable online course for United World Colleges; to WhatFutures meaningful inclusion of young volunteer's voices in the strategic planning of an international humanitarian organisation, all were forged in the heat of real need. On reflection, this is no accident, as designing coordinated participation on existing social media technologies gives research an opportunity to engage with real world problems, in high fidelity and at scale. In this way, unplatformed design can be leveraged by collaborating organisations to work at scale, particularly in contexts that are resource constrained or where the barriers of participation need to be lowered (e.g. NGOs, developing contexts, distributed populations).

\section{CONCLUSION}

We have presented a model for the unplatformed design of coordinated participation. The model consists of a conceptualization of social media technologies as a design material, with four material qualities morphology, role, representation of activity and permeability and the ways in which they can be manipulated through configuration, hard augmentation and soft augmentation. We have demonstrated the utility of this model from our investigation of three case studies of coordinated participation, and have pointed to the implications of unplatformed design as drawing attention to new resources for design around the appropriation of existing social media technologies, which may have ramifications on both the design of these technologies and on the design of coordinated participation going forward.

\section{ACKNOWLEDGMENTS}

The authors would like to thank Haley MacLeod for her helpful suggestions and for answering our questions about ARC. This work was funded under the EPSRC Centre for Doctoral Training in Digital Civics at Newcastle University (EP/L016176/1). 


\section{REFERENCES}

[1] Arpita Bhattacharya, Calvin Liang, Emily Y. Zeng, Kanishk Shukla, Miguel E.R. Wong, Sean A. Munson, and Julie A. Kientz. 2019. Engaging teenagers in asynchronous online groups to design for stress management. Proc. 18th ACM Int. Conf. Interact. Des. Child. IDC 2019 (2019), 26-37. DOI:https://doi.org/10.1145/3311927.3323140

[2] E Blevis, Y Lim, and Erik Stolterman. 2006. Regarding software as a material of design. Proc. Des. Res. ... (2006), 1-18.

[3] Herbert Blumler. 1954. What is Wrong with Social Theory? Am. Sociol. Rev. 19, 1 (1954), 3-10. DOI:https://doi.org/10.2307/2088165

[4] Gregor Broll and Steve Benford. 2005. Seamful Design for Mobile Games. Design (2005), 1-19. DOI:https://doi.org/10.1007/11558651_16

[5] K. CassLe Kresnye, Ben Jelen, Maria K. Wolters, Juan F. Maestre, Mona Y. Alqassim, and Katie A. Siek. 2019. Lessons Learned from Research via Private Social Media Groups. Conf. Hum. Factors Comput. Syst. - Proc. (2019), 1-8.

DOI:https://doi.org/10.1145/3290607.3299055

[6] Hanna Celina, Kharrufa Ahmed, Anne Preston, Rob Comber, and Patrick Olivier. 2016. SOLE Meets MOOC: Designing Infrastructure for Online SelfOrganised Learning with a Social Mission. Dis 2016 (2016), 484-496.

DOI:https://doi.org/10.1145/2901790.2901848

[7] Hanna Celina, Clement Lee, Patrick Olivier, and Ahmed Kharrufa. 2018. LearningCircle.io: Lessons Learned from Organising Courses with and without a Dedicated Platform. EdMedia+ Innov. Learn. Association for the Advancement of Computing in Education (AACE) (2018), 76-81.

[8] Matthew Chalmers and Ian MacColl. 2003. Seamful and Seamless Design in Ubiquitous Computing. Work. Crossroads Interact. HCI Syst. Issues UbiComp. January (2003), 8. Retrieved from http://citeseerx.ist.psu.edu/viewdoc/download?doi= 10.1.1.104.9538\&rep=rep1\&type $=$ pdf

[9] Camille Cobb, Ted McCarthy, Annuska Perkins, Ankitha Bharadwaj, Jared Comis, Brian Do, and Kate Starbird. 2014. Designing for the deluge: Understanding \& supporting the distributed, collaborative work of crisis volunteers. Proc. ACM Conf. Comput. Support. Coop. Work. CSCW (2014), 888-899.

DOI:https://doi.org/10.1145/2531602.2531712

[10] Elizabeth G Cohen and Rachel A. Lotan. 2014. Designing groupwork: Strategies for the heterogeneous classroom. Teachers College Press,
NY.

[11] Clara Crivellaro, Rob Anderson, Daniel LambtonHoward, Tom Nappey, Patrick Olivier, Vasilis Vlachokyriakos, Alexander Wilson, and Pete Wright. 2019. Infrastructuring public service transformation: Creating collaborative spaces between communities and institutions through $\mathrm{HCI}$ research. ACM Trans. Comput. Interact. 26, 3 (2019). DOI:https://doi.org/10.1145/3310284

[12] Clara Crivellaro, Rob Comber, John Bowers, Peter C. Wright, and Patrick Olivier. 2014. A pool of dreams. Proc. 32nd Annu. ACM Conf. Hum. factors Comput. Syst. - CHI '14 (2014), 3573-3582. DOI:https://doi.org/10.1145/2556288.2557100

[13] Jill Dimond, Casey Fiesler, Betsy Disalvo, Jon Pelc, and Amy Bruckman. 2012. Qualitative data collection technologies: A comparison of instant messaging, email, and phone. GROUP'12 - Proc. ACM 2012 Int. Conf. Support Gr. Work 1 (2012), 277-280. DOI:https://doi.org/10.1145/2389176.2389218

[14] Alan Dix. 2007. Designing for Appropriation. Proc. 21st BCS HCI Gr. Conf. 2, September (2007), 2730. Retrieved from http://eprints.lancs.ac.uk/41618/

[15] P. Dourish. 2003. The Appropriation of Interactive Technologies. CSCW 12, 4 (2003), 465-490. DOI:https://doi.org/https://doi.org/10.1023/A:10261 49119426

[16] Paul Dourish. 2017. The Stuff of Bits: An Essay on the Materialities of Information (1st ed.). The MIT Press.

[17] Howard Giles, Scott Reid, and Jake Harwood. 2010. The Dynamics of Intergroup Communication. Peter Lang.

[18] Joseph A Gonzales, Casey Fiesler, and Amy Bruckman. 2015. Towards an Appropriable CSCW Tool Ecology : Lessons from the Greatest International Scavenger Hunt the World Has Ever Seen. Cscw (2015), 946-957. DOI:https://doi.org/10.1145/2675133.2675240

[19] Francisco Jose Grajales, Samuel Sheps, Kendall Ho, Helen Novak-Lauscher, and Gunther Eysenbach. 2014. Social media: A review and tutorial of applications in medicine and health care. Journal of Medical Internet Research. DOI:https://doi.org/10.2196/jmir.2912

[20] Jennifer Hill, W. Randolph Ford, and Ingrid G. Farreras. 2015. Real conversations with artificial intelligence: A comparison between human-human online conversations and human-chatbot conversations. Comput. Human Behav. 49, (2015), 245-250. 
DOI:https://doi.org/10.1016/j.chb.2015.02.026

[21] Youyang Hou and Cliff Lampe. 2015. Social media effectiveness for public engagement: Examples of small nonprofits. Conf. Hum. Factors Comput. Syst. - Proc. 2015-April, (2015), 3107-3116. DOI:https://doi.org/10.1145/2702123.2702557

[22] Robert Johansen. 1988. Groupware: computer support for business teams. The Free Press.

[23] David W. Johnson and Roger T. Johnson. 1999. Making cooperative learning work. Theory Pract. 38, 2 (1999), 67-73.

DOI:https://doi.org/10.1080/00405849909543834

[24] Nabil N. Kamel and Robert M. Davison. 1998. Applying CSCW technology to overcome traditional barriers in group interactions. Inf. Manag. 34, 4 (1998), 209-219. DOI:https://doi.org/10.1016/S0378-7206(98)000561

[25] Daniel Lambton-Howard, Robert Anderson, Kyle Montague, Andrew Garbett, Shaun Hazeldine, Carlos Alvarez, John A. Sweeney, Patrick Olivier, and Ahmed Kharrufa. 2019. WhatFutures :

Designing Large-Scale Engagements on WhatsApp. WhatFutures Des. Large-Scale Engag. WhatsApp. CHI Conf. Hum. Factors Comput. Syst. Proc. (CHI 2019), May 4-9, 2019, Glas. Scotl. UK. ACM, New York, NY, USA, 14 (2019), 1-14. DOI:https://doi.org/10.1145/3290605.3300389

[26] Laura Lovett. 2019. Facebook unveils health support groups, new privacy feature for medical topics. mobihealthnews.com. Retrieved September 9, 2019 from https://www.mobihealthnews.com/content/facebook -unveils-health-support-groups-new-privacyfeature-medical-topics

[27] Jonas Löwgren and Erik. Stolterman. 2004. Thoughtful Interaction Design: A Design Perspective on Information Technology. MIT Press.

[28] Paul Benjamin Lowry, Tom L. Roberts, Nicholas C. Romano, Paul D. Cheney, and Ross T. Hightower. 2006. The impact of group size and social presence on small-group communication: Does computermediated communication make a difference? Small Gr. Res. 37, 6 (2006), 631-661. DOI:https://doi.org/10.1177/1046496406294322

[29] Haley MacLeod, Ben Jelen, Annu Prabhakar, Lora Oehlberg, Katie Siek, and Kay Connelly. 2017. Asynchronous Remote Communities (ARC) for Researching Distributed Populations. EAI Endorsed Trans. Pervasive Heal. Technol. 3, 11 (2017), 152898. DOI:https://doi.org/10.4108/eai.18-72017.152898
[30] Juan F Maestre, Haley Macleod, Ciabhan L Connelly, Julia C Dunbar, Jordan Beck, Katie A Siek, and Patrick C Shih. 2018. Defining Through Expansion: Conducting Asynchronous Remote Communities ( ARC) Research with Stigmatized Groups. Proc. SIGCHI Conf. Hum. Factors Comput. Syst. - CHI'18 (2018), 1-13. DOI:https://doi.org/10.1145/3173574.3174131

[31] Jane McGonigal. 2011. Reality is Broken: Why Games Make Us Better and How They Can Change the World. Penguin.

[32] William Odom, Ron Wakkary, Youn-kyung Lim, Audrey Desjardins, Bart Hengeveld, and Richard Banks. 2016. From Research Prototype to Research Product. (2016), 2549-2561.

DOI:https://doi.org/10.1145/2858036.2858447

[33] Raghav Ohri. 2018. Banks serving summons to defaulters through WhatsApp, emails. Financial Times. Retrieved May 21, 2019 from https://economictimes.indiatimes.com/industry/ban king/finance/banking/banks-serving-summons-todefaulters-through-whatsappemails/articleshow/65630866.cms

[34] Annu Sible Prabhakar, Lucia Guerra-Reyes, Vanessa M. Kleinschmidt, Ben Jelen, Haley MacLeod, Kay Connelly, and Katie A. Siek. 2017. Investigating the Suitability of the Asynchronous, Remote, Community-based Method for Pregnant and New Mothers. Proc. 2017 CHI Conf. Hum. Factors Comput. Syst. - CHI '17 (2017), 4924 4934.

DOI:https://doi.org/10.1145/3025453.3025546

[35] Kate Starbird and Leysia Palen. 2011.

"Voluntweeters": Self-organizing by digital volunteers in times of crisis. Conf. Hum. Factors Comput. Syst. - Proc. (2011), 1071-1080. DOI:https://doi.org/10.1145/1978942.1979102

[36] Gunnar Stevens, Volkmar Pipek, and Volker Wulf. 2009. Appropriation infrastructure: Supporting the design of usages. In Lecture Notes in Computer Science (including subseries Lecture Notes in Artificial Intelligence and Lecture Notes in Bioinformatics). DOI:https://doi.org/10.1007/9783-642-00427-8_4

[37] Pierre Tchounikine. 2017. Designing for Appropriation: A Theoretical Account. HumanComputer Interact. 32, 4 (2017), 155-195. DOI:https://doi.org/10.1080/07370024.2016.12032 63

[38] Thea Turner, Pernilla Qvarfordt, Jacob T Biehl, Gene Golovchinsky, Maribeth Back, Hillview Ave, and Palo Alto. 2010. Exploring the Workplace Communication Ecology. User Charact. Large- 
Scale Track. 10, 15 (2010), 841-850.

DOI:https://doi.org/10.1145/1753326.1753449

[39] Amy Voida, Ellie Harmon, and Al Ani Ban. 2011. Homebrew databases: Complexities of everyday information management in nonprofit organizations. Conf. Hum. Factors Comput. Syst. Proc. (2011), 915-924.

DOI:https://doi.org/10.1145/1978942.1979078

[40] Mark Weiser. 1994. Creating the invisible interface (invited talk). ACM Conf on User Interface Software and Technology (UIST94).
[41] Etienne Wenger. 1998. Communities of Practice: Learning, Meaning, and Identity. Cambridge University Press.

[42] WhatsApp. 2019. WhatsApp Business App. Retrieved September 9, 2019 from https://www.whatsapp.com/business/

[43] Andrea Wiggins. 2013. Free As In Puppies: Compensating for ICT Constraints in Citizen Science. Proc. 2013 Conf. Comput. Support. Coop. Work. ACM (2013), 1469.

DOI:https://doi.org/10.1145/2441776.2441942 